\title{
PENURUNAN BOD, COD, DAN ZAT WARNA LIMBAH PENCELUPAN DENGAN FITOEKSTRAKSI MENGGUNAKAN KIAMBANG (Salvinia natans)
}

\author{
I G.A. Kunti Sri Panca Dewi*, Putu Suarya, dan Iryanti E.Suprihatin, Wahyu Dwijani S. \\ Jurusan Kimia, Fakultas Matematika dan Ilmu Pengetahuan Alam, Universitas Udayana, \\ Bukit Jimbaran, Badung Telp/Fax : 08124620125 \\ *email : kuntidewi42@yahoo.com
}

\begin{abstract}
This research was conducted to study the potential of the plants 'useless' as kiambang (Salvinia natans) which are easy to find, and not as valuable as textile dyeing waste handling media. Treatment technique used is to replace the growth medium with the waste in question in this case of waste taken in the dyeing industry. The concentration of methylene bluein waste of dye, and congo red, before and after treatment, determined by spectrophotometry. Fluid absorbance was measured at a wavelength of $664 \mathrm{~nm}$ for methylene blue and $496 \mathrm{~nm}$ for congo red. Long time treatment used is 6, 12, 18, 24, 30, 36, and 48 hours. These results indicate that kiambang (Salvinia natans) is useful to lower BOD and COD of waste dyeing, although its ability to reduce the content of the dye congo red and blue methyl insignificant. This may be caused by too concentrated the dyeing waste.
\end{abstract}

Keywords: fitoekstraksi, textile waste, congo red, methyl blue

\begin{abstract}
Abstrak
Penelitian ini dilakukan untuk mempelajari potensi tanaman 'tidak berguna' seperti kiambang (Salvinia natans) yang sangat mudah ditemukan dan tidak berharga sebagai media penanganan limbah pewarnaan tekstil. Teknik perlakuan yang dipakai adalah dengan menggantikan media tumbuh dengan limbah yang dimaksud dalam hal ini limbah yang diambil di industri pencelupan. Konsentrasi zat warna metilen biru dan congo red, sebelum dan setelah perlakuan, ditentukan secara spektrofotometri. Absorbansi cairan diukur pada panjang gelombang $664 \mathrm{~nm}$ untuk metilen biru dan $496 \mathrm{~nm}$ untuk congo red. Lama waktu perlakuan yang digunakan adalah 6, 12, 18, 24, 30 36, dan 48 jam. Hasil penelitian ini menunjukan bahwa kiambang (Salvinia natans) bermanfaat menurunkan BOD dan COD dari limbah pencelupan, walaupun kemampuan menurunkan kandungan zat warna congo red dan metil biru tidak signifikan. Hal ini mungkin disebabkan oleh terlalu pekatnya limbah pencelupan tersebut.
\end{abstract}

Kata kunci: fitoekstraksi, limbah tekstil, congo red, metil biru

\section{Pendahuluan}

Absorpsi zat oleh tanaman menurut Soemirat (2003) dapat terjadi melalui akar (terutama untuk zat anorganik dan zat hidrofilik), daun (bagi zat yang lipofilik), dan stomata untuk gas. Penyerapan kontaminan dari lingkungan akar oleh tanaman berakibat berkurangnya konsentrasi kontaminan tersebut di lingkungan, sehingga dapat dikatakan sebagai proses fitoremediasi (bioremediasi oleh tanaman semata) lingkungan tersebut (Unterbruner et al., 2007). Bioremediasi dapat pula terjadi oleh tanaman yang bersimbiosis dengan mikroba yang hidup disekitar akarnya. Akar menghasilkan eksudat yang berguna bagi mikroba, sementara mikroba tersebut mampu memecah molekul-molekul kompleks menjadi yang lebih sederhana dan dapat diserap akar. 
Pada gilirannya proses yang dikenal sebagai rhizodegradasi ini mengurangi konsentrasi polutan dari lingkungan (Dzantor, 2007). Metode ini telah banyak digunakan di seluruh dunia, antara lain untuk mendegradasi bahan bakar minyak (Etsuko, 2007; Unterbruner et al., 2007; Suprihatin dkk., 2011), polutan seperti poli hidrokarbon aromatik (Lippencott, 2005), dan senyawa-senyawa perklorat (Nzengung et al., 2004 ; Yifru \& Nzengung, 2008) dari dalam lingkungan tanah. Fitofiltrasi, dilain pihak, merupakan metode penyerapan kontaminan dari dalam air oleh tanaman.

Limbah industri tekstil merupakan salah satu kontributor pencemaran air yang sulit diatasi. Pengolahan limbah dengan cara koagulasi dan oksidasi masih belum memadai untuk mengatasi limbah zat warna industri tekstil. Kelemahan dari koagulasi adalah dihasilkannya endapan yang cukup banyak sehingga diperlukan pengolahan limbah lebih lanjut, sementara dengan metoda oksidasi dibutuhkan lahan yang luas untuk pembuatan kolam oksidasi.

Penanggulangan limbah tekstil dengan metode adsorpsi juga telah banyak dilakukan. Namun metode ini ternyata kurang begitu efektif karena zat warna tekstil yang diadsopsi tersebut masih terakumulasi pada adsorben sehingga diperlukan penanganan lebih lanjut.

Absorpsi oleh tumbuhan, dilain pihak, dipandang lebih sederhana karena relatif tidak memerlukan penanganan lebih lanjut. Polutan, dalam hal ini zat warna, didekomposisi menjadi molekulmolekul sederhana yang diharapkan dapat menjadi unsur hara bagi tumbuhan yang bersangkutan.

Di Bali banyak dijumpai tanaman yang tumbuh di lingkungan perairan, seperti eceng gondok, kangkungan, kiambang, dan lain lain. Kiambang (Salvinia natans) telah banyak dimanfaatkan untuk mengurangi konsentrasi logam berat dalam air (Cerman et al., 2012 ; Dhir et al., 2008 ; Ghosh \& Singh, 2005 ; Gupta \& Devi, 1992). Oleh karena itu perlu dilakukan penelitian terhadap potensi Kiambang (Salvinia natans) sebagai media bioremediasi perairan dari polutan seperti limbah tekstil., dalam hal ini zat warna 'congo red' dan metil biru guna mengetahui efektifitasnya dalam menanggulangi pencemaran air oleh limbah zat warna dari industri tekstil.

Untuk alasan ini, tujuan penelitian ini adalah untuk menganalisis penyerapan zat warna 'congo red' dan metil biru oleh kiambang (Salvenia natans). Tanaman ini dipilih karena mudah tumbuh dan tahan terhadap kondisi perairan yang tercemar. Dalam makalah ini fitofiltrasi atau fitoekstraksi polutan dalam limbah pencelupan dilaporkan.

\section{Metodologi}

\subsection{Alat dan Bahan penelitian}

Bahan-bahan yang digunakan yaitu $\mathrm{KI}, \mathrm{HgCl}_{2}$, $\mathrm{H}_{2} \mathrm{SO}_{4}, \mathrm{NaN}_{3}, \mathrm{MnSO}_{4}, \mathrm{Na}_{2} \mathrm{~S}_{2} \mathrm{O}_{4}, \mathrm{~K}_{2} \mathrm{Cr}_{2} \mathrm{O}_{7}, \mathrm{Ag}_{2} \mathrm{SO}_{4}^{-}$ $\mathrm{H}_{2} \mathrm{SO}_{4}, \mathrm{Fe}\left(\mathrm{NH}_{4}\right)_{2}\left(\mathrm{SO}_{4}\right)_{2}$ (FAS), amylum, ferroin, aquadest. Alat-alat yang digunakan yaitu pipet volume, pipet ukur, pipet tetes, gelas piala (beaker glass), botol BOD, gelas ukur, erlenmeyer, labu ukur, seperangkat alat refluks, corong, dan seperangkat alat titrasi, neraca, dan spektrofotometer UV-Vis.

\subsection{Metode}

\subsubsection{Sampling Air Limbah}

Tiga jerigen $20 \mathrm{~L}$ sampel air limbah diambil dari bak penampungan air limbah Industri pencelupan di Denpasar. Untuk percobaan fitoekstraksi limbah diencerkan $4 \mathrm{x}$, dengan kata lain, masing-masing bak diisi $5 \mathrm{~L}$ limbah dan $15 \mathrm{~L}$ air PAM, kemudian diaduk

\subsubsection{Penyiapan Tanaman}

Tanaman yang digunakan adalah tanaman kiambang (Salvinia natans) yang diambil secara langsung dari habitat hidupnya yaitu di lingkungan perairan di persawahan, kemudian dibiarkan tumbuh dalam air bersih selama 3 hari. Tanaman yang digunakan dipilih dengan ukuran dan jumlah yang sama agar proses fitoekstraksi merata untuk setiap bak pengolahan.

\subsubsection{Pemeriksaan awal}

Sampel air limbah diukur secara langsung $\mathrm{pH}$, suhu, warna dan baunya. Selanjutnya BOD dan COD sampel air limbah tersebut dianalisis mengikuti prosedur standar (Clesceri et.al., 1998), sedangkan intensitas warna congo red dan metilen blue ditentukan secara spektrofotometri.

2.2.4. Penurunan BOD, COD, congo red, dan metilen blue melalui fitoekstraksi

Kiambang dibiarkan tumbuh dan berkembang biak dalam bak kaca berisi $20 \mathrm{~L}$ limbah tekstil yang sudah 
diencerkan 4x (5 L limbah $+15 \mathrm{~L}$ air PAM). Pengenceran dilakukan karena dari penelitian pendahuluan tidak terjadi penurunan BOD dan COD yang memuaskan selama 3 hari, diduga karena konsentrasi polutan yang terlalu pekat. Dari bak diambil 3 sampel air masing-masing $10 \mathrm{~mL}$ untuk diukur absorbansinya dengan spektrofotometer UVVis pada panjang gelombang maksimum dari congo red (496 nm) dan metil biru (664 nm). Dari bak juga diambil 3 buah sampel limbah untuk dianalisis BOD dan CODnya. Hasil pengukuran ini dipakai sebagai konsentrasi awal (waktu "0" jam). Penentuan keempat parameter juga dilakukan pada jam ke 6, 12, 18, 24, 30, 36, dan 48 .

\section{Hasil dan Pembahasan}

Tabel 3.1. Penurunan BOD, COD, dan kandungan zat warna dari limbah encer oleh kiambang. Kandungan zat warna dinyatakan dalam absorbansi pada $664 \mathrm{~nm}$ untuk metilen blue dan 494 nm untuk congo red.

Seperti diketahui BOD adalah Banyaknya oksigen yang dibutuhkan untuk degradasi secara biologi dan COD adalah banyaknya oksigen yang dibutuhkan untuk degradasi secara kimia. Tabel 3.1 menunjukan bahwa perlakuan kiambang dapat menurunkan BOD dan COD. Pada 6 jam pertama baik BOD maupun COD turun dengan cukup tinggi, tetapi pada 6 jam kedua dan ketiga naik bahkan jauh melebihi BOD dan COD limbah sebelum kontak dengan kiambang. Hal ini mungkin disebabkan oleh pada 6 jam pertama itu bakteri belum aktif beraktivitas demikian juga aktivitas kimia belum tinggi sehingga kebutuhan oksigen rendah. Pada jam

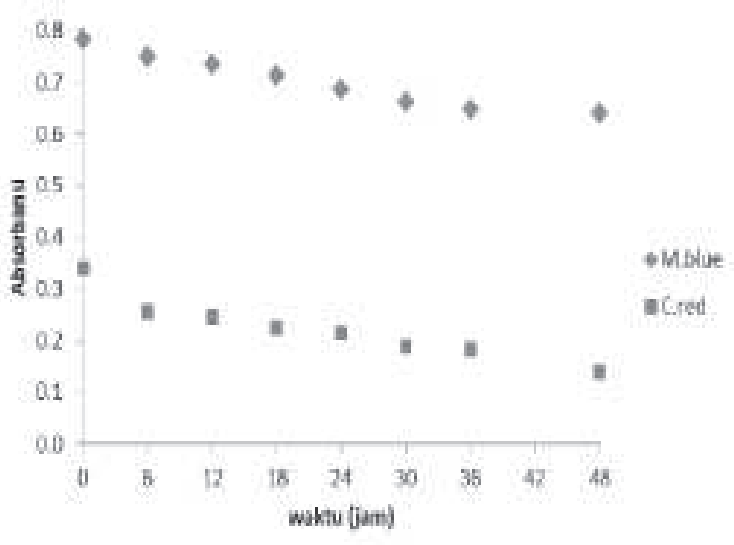

Gambar 3.1.

Penurunan kandungan zat warna

ke-12 dan 18 bakteri dan aktivitas kimia sangat aktif sehingga kebutuhan oksigen naik drastis dan setelah itu yaitu pada jam ke 24 BOD dan COD turun lagi maka bahan-bahan yang harus didegradasi sudah berkurang sehingga kebutuhan oksigen juga berkurang. Penurunan BOD terjadi dari jam ke 24 ke jam ke 30 diikuti oleh jam 18 ke 24, tetapi pada jam-jam berikutnya penurunan BOD kecil. Penurunan COD hampir sama polanya, tetapi sedikit berbeda yaitu penurunan tertinggi terjadi pada jam ke $18 \mathrm{ke}$ jam 24, diikuti oleh 6 jam pertama dan jam ke 30 ke jam ke 36 , sedangkan pada jam-jam yang lain penurunannya kecil. Jadi penurunan BOD yang efektif pada jam ke 30 dan penurunan COD pada jam ke 36 .

Hasil analisis zat warna menunjukan bahwa penurunan congo red lebih besar dibandingkan

Tabel 3.1. Hasil Analisis BOD, COD dan Kandungan Zat Warna Metilen Blue dan Congo Red

\begin{tabular}{ccccc}
\hline Waktu (jam) & BOD $(\mathbf{m g} / \mathbf{L})$ & COD $(\mathbf{m g} / \mathbf{L})$ & $\mathbf{A}_{\mathbf{6 6 4}}$ (M.blue) & $\mathbf{A}_{\mathbf{4 9 6}}(\mathbf{C . r e d})$ \\
\hline 0 & $55.78 \pm 3.89$ & $93.21 \pm 2.96$ & $0.781 \pm 0.018$ & $0.340 \pm 0.058$ \\
6 & $44.15 \pm 5.24$ & $71.78 \pm 1.11$ & $0.749 \pm 0.016$ & $0.255 \pm 0.033$ \\
12 & $67.28 \pm 5.69$ & $101.85 \pm 2.23$ & $0.735 \pm 0.011$ & $0.246 \pm 0.030$ \\
18 & $72.14 \pm 6.40$ & $106.70 \pm 1.11$ & $0.713 \pm 0.013$ & $0.223 \pm 0.015$ \\
24 & $50.76 \pm 5.63$ & $82.02 \pm 1.22$ & $0.685 \pm 0.016$ & $0.213 \pm 0.009$ \\
30 & $35.26 \pm 5.60$ & $79.09 \pm 1.07$ & $0.660 \pm 0.014$ & $0.186 \pm 0.010$ \\
36 & $33.16 \pm 5.54$ & $64.99 \pm 1.73$ & $0.646 \pm 0.012$ & $0.182 \pm 0.006$ \\
48 & $30.06 \pm 2.74$ & $60.96 \pm 1.76$ & $0.639 \pm 0.010$ & $0.138 \pm 0.007$ \\
\hline
\end{tabular}


dengan metil blue. Pola penurunan kedua zat warna ini hampir sama yaitu pada 6 jam pertama penurunannya tertinggi dan untuk metil blue penurunan efektif pada jam ke 36 dan congo red pada jam ke 48. Penurunan BOD sebesar 46,11\% pada jam ke 48 dari nilai BOD awal (BOD limbah). Penurunan COD sebesar 34,60\% dari COD awal. Penurunan Congo red 59,41\% dan metil biru hanya $18,18 \%$

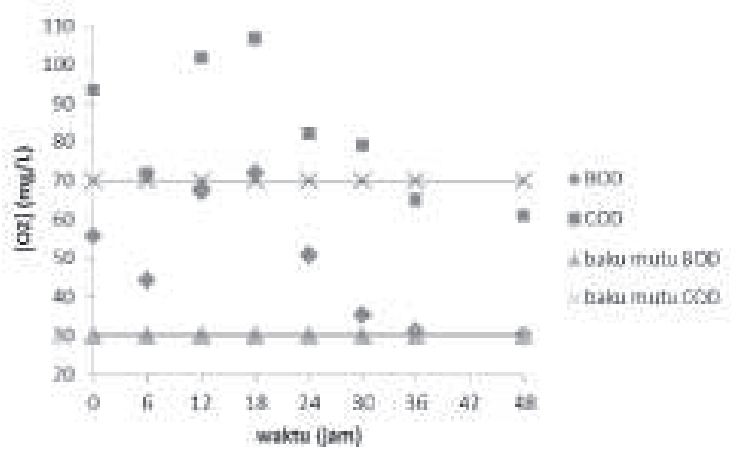

Gambar 3.2.

Penurunan BOD dan COD

\section{Simpulan dan Saran}

Tanaman kiambang dapat menurunkan BOD, COD, konsentrasi zat warna metil blue dan congo red. Diantara parameter ini, maka dapat disimpulkan kiambang paling efektif menurunkan zat warna congo red dan kurang efektif untuk menurunkan zat warna metil biru.

\section{Ucapan Terima Kasih}

Penulis mengucapkan terima kasih kepada Dirjen Dikti melalui LPPM untuk pendanaan penelitian. Kepada pabrik pencelupan di Jalan P. Rote yang tidak menghendaki disebut namanya kami sangat berterima kasih karena sudah diijinkan mengambil sampel limbahnya.

\section{Daftar Pustaka}

Cerman Z, Striffler BF, Barthlott W. 2012. Dry in the water: the superhydrophobic water fern Salvinia - a model for biomimetic surfaces. In: Gorb SN, editor. Functional surfaces in biology. Berlin, Heidelberg: Springer [in press].
Dhir, B., Sharmila P. and Pardha Saradhi, 2008. Photosynthetic performance of Salvinia natansexposed to chromium and zinc rich wastewater.Braz. J. Plant Physiol. vol.20 no.1.

Dogra, S.K., and Dogra, S., 1984, Physical Chemistry Through Problems, a.b. Mansyur, U., Universitas Indonesia, Jakarta.

Dzantor , E. K., (2007). Phytoremediation: the state of rhizosphere 'engineering' for accelerated rhizodegradation of xenobiotic contaminants"., Journal of Chemical Technology and Biotechnology, Vol.82(3), pp. 228-32.

Etsuko, K. (2007), Effect of Rhizodegradation in Diesel-contaminated Soil under Different Soil Conditions., Plant Prod Sci., vol. 10(1): 105-11

Ghosh, M. and S. P. Singh, 2005. A review on phytoremediation of heavy metals and utilization of its byproducts. Appl. Ecology and Env. Res. 3(1):1-18.

Gupta, M. and Devi, 1992. Environmental Contamination and Toxicology Cadmium Sensitivity Inducing Structural Responses in Salvinia molesta Mitchell. Bull. Environ. Contam. Toxicol. 49:436-443.

Hamdaoui, O., and Chiha, M., 2007, Removal of Methylene Blue from Aqueous Solutions by Wheat Bran, Acta Chim, 54,407-418.

Houas, A., Lachheb, H., and Ksibi, M., 2001, Photocatalytic Degradation Pathway of Methylene Blue in water, Appl. Catal.B. Environ., 31, 145-157.

Lippencott, R.J., (2005).Evaluating Rhizodegradation of petroleum hydrocarbons and polyaromatic hydrocarbons in wetland sediments containing Spartina patens., dissertation, The State University of New Jersey, USA.

Madhu,G.M., Lourdu, An.R.M.A., Vasanta, Kumar Pai.K., and Rao, Shreyas., 2007, Photodegradation of methylene bluedye using $\mathrm{UV} / \mathrm{BaTiO}_{3}$, $\mathrm{UV} / \mathrm{H}_{2} \mathrm{O}_{2}$ and $\mathrm{UV} / \mathrm{H}_{2} \mathrm{O}_{2} / \mathrm{BaTiO}_{3}$ Indian Journal of Chemical Teknologi, 14, 139-144.

Nzengung VA, Penning H, O'Niell W. 2004., Mechanistic changes during phytoremediation of perchlorate under different root-zone conditions., Int J Phytoremediation.;6(1):63-83 
Riswiyanto, S., Bakri, R., Prawira, B. R., 2005, Studi Degradasi Zat Warna Tekstil (Alizarin RedDirect Red 81) Menggunakan Metode Fotokatalitik dengan Suspensi $\mathrm{TiO}_{2}$ dan Sinar UV C, Sains Indonesia, 10, 14-21.

Rusmidah, A., Ooi,B.,2006 Photodegradation Of New Methylene Blue $N$ in Aqueous Solution Using Zinc Oxide And Titanium Dioxide as Catalyst; Malaysia: 31-42

Soemirat, J.(editor), 2003. Toksikologi Lingkungan. Gajah Mada University Press. Yogyakarta

Suprihatin, I.E., Sulihingtyas, W.D., Suyasa, IW.B., 2011. Rhyzodegradation of oil waste, proceeding on the $3^{\text {rd }}$ International Conference on Bioscinces and Biotechnology, Bali, September 2011.

Unterbruner, R. , Wieshammer, G., Hollender U., Felderer, B., Zivcovic, M.W., Puschenreiter, M., and Wenzel, W.W., (2007)., Plant and fertilizer effect on rhizodegradation of crude oil in two soils with different nutrients status, Plant Soil, 300:117- 126.

Yifru DD, Nzengung VA, (2008).Organic carbon biostimulates rapid rhizodegradation of perchlorate.,Environ Toxicol Chem., vol. 27(12), pp. 2419-26. 